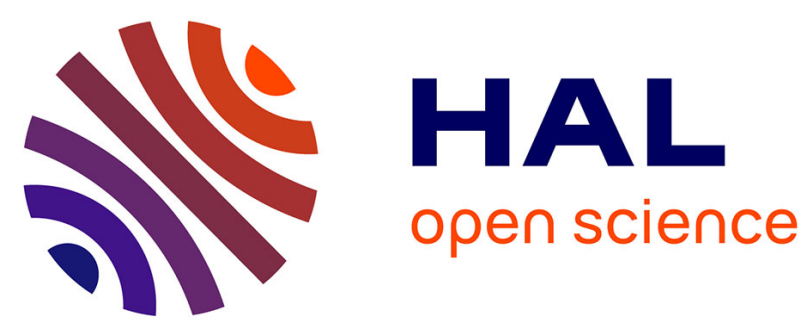

\title{
Atomic Insights into Aluminium-Ion Insertion in Defective Anatase for Batteries
}

Christophe Legein, Benjamin Morgan, Franck Fayon, Toshinari Koketsu, Jiwei Ma, Monique Body, Vincent Sarou-kanian, Xian-kui Wei, Marc Heggen, Olaf Borkiewicz, et al.

\section{To cite this version:}

Christophe Legein, Benjamin Morgan, Franck Fayon, Toshinari Koketsu, Jiwei Ma, et al.. Atomic Insights into Aluminium-Ion Insertion in Defective Anatase for Batteries. Angewandte Chemie International Edition, 2020, 10.1002/anie.202007983 . hal-02947103

\section{HAL Id: hal-02947103 https://hal.sorbonne-universite.fr/hal-02947103}

Submitted on 23 Sep 2020

HAL is a multi-disciplinary open access archive for the deposit and dissemination of scientific research documents, whether they are published or not. The documents may come from teaching and research institutions in France or abroad, or from public or private research centers.
L'archive ouverte pluridisciplinaire HAL, est destinée au dépôt et à la diffusion de documents scientifiques de niveau recherche, publiés ou non, émanant des établissements d'enseignement et de recherche français ou étrangers, des laboratoires publics ou privés. 


\title{
Atomic Insights into Aluminium-Ion Insertion in Defective
} Anatase for Batteries

\author{
Christophe Legein $^{[a]}$, Benjamin J. Morgan ${ }^{[b]}$, Franck Fayon ${ }^{[c]}$, Toshinari Koketsu ${ }^{[\mathrm{d}]}$, Jiwei Ma ${ }^{[\mathrm{e},[\mathrm{g}]}$, \\ Monique Body ${ }^{[a]}$, Vincent Sarou-Kanian ${ }^{[\mathrm{c}]}$, Xian-Kui Wei ${ }^{[\mathrm{f]}}$, Marc Heggen ${ }^{[\mathrm{f}]}$, Olaf J. Borkiewicz ${ }^{[\mathrm{i}]}$, \\ Peter Strasser ${ }^{[\mathrm{d}]}$, and Damien Dambournet ${ }^{\left.[\mathrm{e}],[]_{*}\right]_{*}}$
}

[a] Prof. C. Legein, Dr. M. Body

Institut des Molécules et des Matériaux du Mans (IMMM), UMR 6283 CNRS, Le Mans Université,

Avenue Olivier Messiaen, 72085 Le Mans Cedex 9, France

[b] Dr. B. J. Morgan

Department of Chemistry

University of Bath

BA2 7AY Bath, United Kingdom

[c] Dr. F. Fayon, Dr. V. Sarou-Kanian

CNRS, CEMHTI UPR3079

Université d'Orléans

F-45071 Orléans, France

[d] Dr. T. Koketsu, Prof. P. Strasser

The Electrochemical Energy, Catalysis, and Materials Science Laboratory, Department of Chemistry

Technical University Berlin

10623 Berlin, Germany

[e] Pr. J. Ma, Dr. D. Dambournet

Sorbonne Université, CNRS,

Physico-chimie des électrolytes et nano-systèmes interfaciaux, PHENIX,

F-75005 Paris, France

E-mail: damien.dambournet@sorbonne-universite.fr

[f] Dr. D. Dambournet

Réseau sur le Stockage Electrochimique de l'Energie (RS2E)

FR CNRS 3459

80039 Amiens cedex, France

[g] Pr. J. Ma

Institute of New Energy for Vehicles,

School of Materials Science and Engineering, Tongji University

Shanghai 201804, China

[h] Dr. X. Wei, Dr. M. Heggen

Forschungszentrum Juelich $\mathrm{GmbH}$

52425 Juelich, Germany

[i] Dr. O. J. Borkiewicz

X-ray Science Division, Advanced Photon Source

Argonne National Laboratory

9700 South Cass Avenue, Argonne, Illinois 60439, United States

Supporting information for this article is given via a link at the end of the document.((Please delete this text if not appropriate))

\begin{abstract}
Aluminium batteries constitute a safe and sustainable high-energy-density electrochemical energy-storage solution. Viable Al-ion batteries require suitable electrode materials that can readily intercalate high-charge $\mathrm{Al}^{3+}$ ions. Here, we investigate the $\mathrm{Al}^{3+}$ intercalation chemistry of anatase $\mathrm{TiO}_{2}$ and how chemical modifications influence the accommodation of $\mathrm{Al}^{3+}$ ions. We use fluoride- and hydroxide-doping to generate high concentrations of titanium vacancies. The coexistence of these hetero-anions and titanium vacancies leads to a complex insertion mechanism, attributed to three distinct types of host sites: native interstitials sites, single vacancy sites, and paired vacancy sites. We demonstrate that $\mathrm{Al}^{3+}$ induces a strong local distortion within the modified $\mathrm{TiO}_{2}$ structure, which affects the insertion properties of the neighbouring host sites. Overall, specific structural features induced by the intercalation of highly-polarizing $\mathrm{Al}^{3+}$ ions should be considered when designing new electrode materials for polyvalent batteries.
\end{abstract}

\section{Introduction}

Lithium-ion batteries are used for electrochemical storage in multiple applications, ranging from electronic devices to electric vehicles and to grid storage. The continuing growth in global energy demands calls for the development of new energy storage technologies with increased efficiencies, decreased environmental impact, and higher energy densities. Concerns about whether lithium resources can meet projected future energy-storage needs has motivated research into alternative ion-insertion electrochemistries. ${ }^{[1-4]}$ One possible alternative to lithium-ion batteries is to exploit aluminium-ion intercalation chemistries. Aluminium-ion batteries would take advantage of the greater abundance of aluminium compared to lithium, and they offer the potential for increased energy densities and improved battery safety. ${ }^{[5]}$ Aluminium is the third most abundant element, and the most abundant metal, in the Earth's crust, making it significantly cheaper than lithium. ${ }^{[6]}$ Furthermore, 
aluminium can exchange up to three electrons per ion, versus one electron per ion for lithium, and has a high density $\left(2.7 \mathrm{~g} \mathrm{~cm}^{-}\right.$ ${ }^{3}$ at $25^{\circ} \mathrm{C}$ ). This gives a high theoretical volumetric capacity of $8056 \mathrm{mAh} \mathrm{cm}^{-3}$ for aluminium, versus $2042 \mathrm{mAh} \mathrm{cm}^{-3}$ for lithium. ${ }^{[7]}$

A key challenge in developing aluminium-ion batteries is identifying suitable electrode materials, that can reversibly intercalate $\mathrm{Al}^{3+}$ ions. ${ }^{[8]}$ The ionic radius of the $\mathrm{Al}^{3+}$ ion $(0.53 \AA)$ is smaller than that of $\mathrm{Li}^{+}(0.76 \AA)$, and one might therefore expect to find many materials that readily intercalate $\mathrm{Al}^{3+}$ insertion. In practice, strong interactions between high formal-charge $\mathrm{Al}^{3+}$ and the anionic substructure of the host material mean insertion is often severely limited. The polarizing power of an ion is given by $Z / r^{2}$, where $Z$ and $r$ are its charge and its radius, respectively. The polarizing power describes the degree to which a given cation attracts and distorts the electron clouds of nearby anions. The polarizing power of $\mathrm{Al}^{3+}\left(10.68 \mathrm{e}^{-2}\right)$ is much greater than that of $\mathrm{Li}^{+}\left(1.73 \mathrm{e} \AA^{-2}\right)$, consistent with a stronger electrostatic interaction between $\mathrm{Al}^{3+}$ and the anionic sublattice of an intercalation host. This stronger interaction means that, in general, the intercalation behaviour of polyvalent cations often strongly differs from that of lithium ions. ${ }^{[4]}$

Because few materials are known that readily accommodate $\mathrm{Al}^{3+}$ ions, there is a limited understanding of $\mathrm{Al}^{3+}$ intercalation chemistry. Efficient aluminium storage has been reported for graphite cathode materials, but this relies on anionic intercalation of $\mathrm{AlCl}_{4}^{-}$species, as opposed to intercalation of trivalent $\mathrm{Al}^{3+}{ }^{[9]}$ Other organic compounds have also been found to be electrochemically active, again through anionic intercalation. ${ }^{[10]}$ Because of the difficulty in identifying suitable $\mathrm{Al}^{3+}$-host materials, a limited number of studies have explored $\mathrm{Al}^{3+}$-intercalation in inorganic frameworks. ${ }^{[5,11-19]}$ One strategy for identifying new Al-cathode materials is to first build a detailed understanding of the intercalation (electro)chemistry of known, viable Al-intercalation hosts; in particular, seeking to understand the local chemical environment of inserted $\mathrm{Al}$ in these materials, and how this affects electrochemical performance.

Anatase $\mathrm{TiO}_{2}$ consists of a three-dimensional network of cornerand edge-sharing $\mathrm{TiO}_{6}$ octahedra, with interstitial sites that can readily accommodate lithium and sodium ions. ${ }^{[20,21]}$ We have previously shown that anatase $\mathrm{TiO}_{2}$ can be chemically modified through monovalent-ion $\left(\mathrm{F}^{-}, \mathrm{OH}^{-}\right)$doping, producing cation vacancies that allow reversible intercalation of polyvalent $\mathrm{Mg}^{2+}$ and $\mathrm{Al}^{3+}$ cations. ${ }^{[22]}$ The insertion behaviours of these two cations are qualitatively different: while $\mathrm{Mg}$ can fully occupy all available titanium vacancies, $\mathrm{Al}^{3+}$ cations occupy barely half of the available sites. In the study presented herein, we further investigate the $\mathrm{Al}^{3+}$ intercalation mechanism in cation-deficient anatase $\mathrm{TiO}_{2}$, to resolve specific details of $\mathrm{Al}^{3+}$ intercalation chemistry in this model host electrode material. Our results indicate a complex insertion mechanism involving a variety of insertion sites: isolated single-vacancy sites, adjacent-pair double-vacancy sites, and native interstitial sites. The identities of the surrounding anions at specific insertion sites and the polarizing power of $\mathrm{Al}^{3+}$ ions are highlighted as key factors that impact the total number of inserted ions.

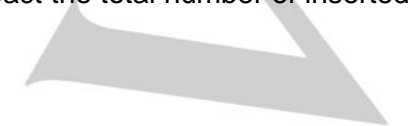

\section{Results and Discussion}

Figure 1a shows a typical galvanostatic first discharge/charge curves $^{[23]}$ for an anatase electrode with $\sim 22 \% \mathrm{Ti}$ vacancies $\left(\mathrm{Ti}_{0.78} \square_{0.22} \mathrm{O}_{1.12} \mathrm{~F}_{0.40}(\mathrm{OH})_{0.48}\right)^{[24]}$. The discharge and charge capacities correspond to the insertion of $\sim 0.103\left(117 \mathrm{mAh} \mathrm{g}^{-1}\right)$ and $\sim 0.080 \mathrm{Al}^{3+}\left(92 \mathrm{mAh} \mathrm{g}^{-1}\right)$ per formula unit, respectively. These values are three-times higher than measured for defectfree $\mathrm{TiO}_{2}{ }^{[18,22]}$ To confirm the electrochemical insertion of $\mathrm{Al}^{3+}$ ions into the structure, high-angle annular dark-field (HAADF) imaging with a scanning transmission electron microscope (STEM) coupled with energy-dispersive X-ray (EDX) spectroscopy was performed on the discharged electrode (Figure1b,c). The resulting data show that aluminium insertion extends throughout the particle giving a homogenous distribution of $\mathrm{Al}$ at the nanometer scale. Quantitative analysis obtained by EDX indicates an Al/Ti molar ratio of 0.13 . Considering a threeelectron transfer per inserted ion, this number matches the experimental capacity, further supporting the insertion of $\mathrm{Al}^{3+}$
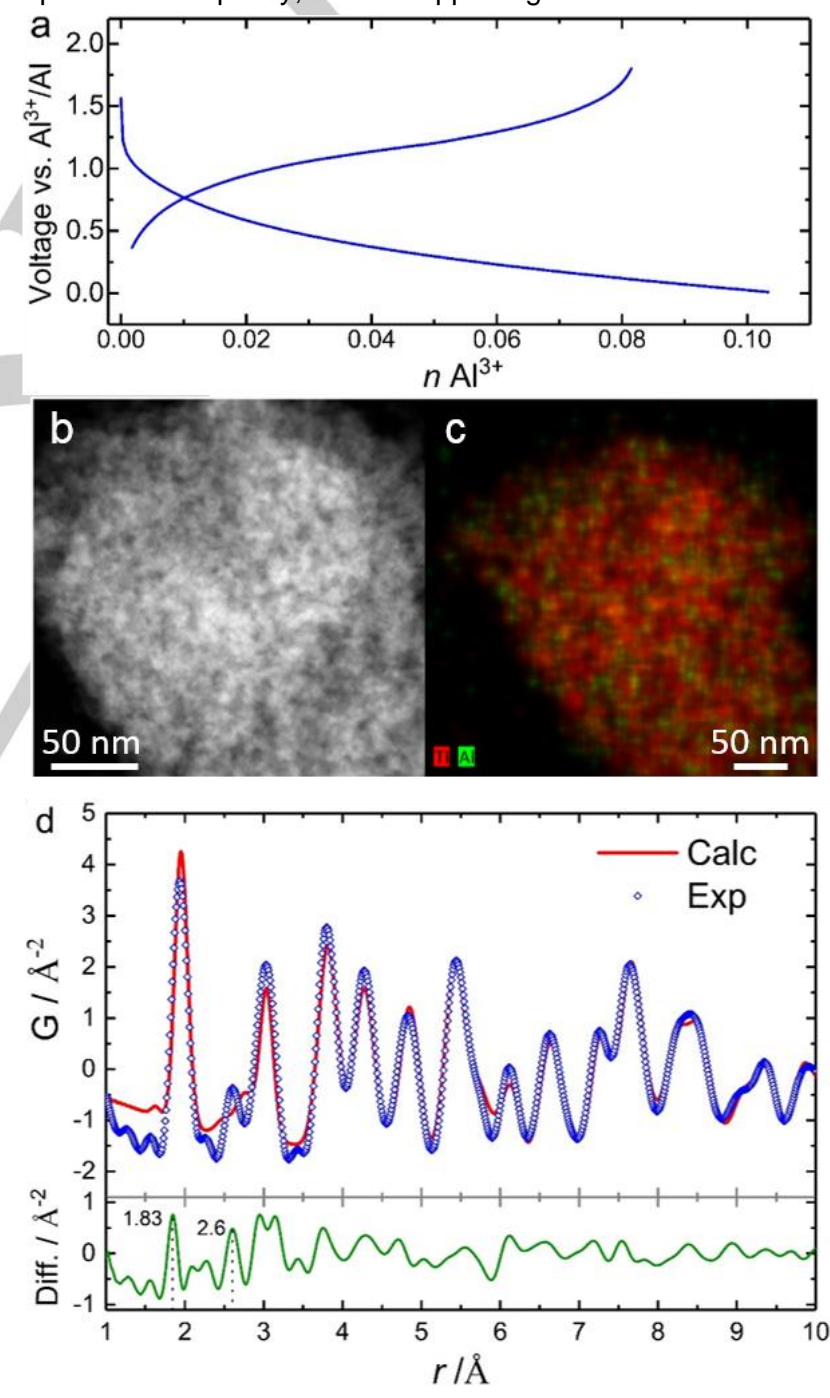

Figure 1. (a) Galvanostatic first discharge and charges curves obtained for $\mathrm{Ti}_{0.78} \square_{0.22} \mathrm{O}_{1.12} \mathrm{~F}_{0.40}(\mathrm{OH})_{0.48}$ electrode cycled vs. $\mathrm{Al}^{3+} / \mathrm{Al}$ under $20 \mathrm{~mA} \mathrm{~g}{ }^{-1}$ at $25^{\circ} \mathrm{C}$. (b,c) HAADF-STEM image measured on the discharged electrode and the corresponding EDX mapping acquired at the $\mathrm{K}$ edge of $\mathrm{Al}$ (green) and $\mathrm{Ti}$ (red) elements overlaid in the image. The measured atomic percentages (at\%) are 88.5 at\% for $\mathrm{Ti}$ and 11.5 at\% for Al. (d) PDF refinement obtained on the discharged electrode. Green line, difference curve between calculated and experimental data. 
The continuous decrease of the voltage-composition curve is typical of solid-solution behaviour. To confirm such a mechanism, the atomic structure of a discharged electrode was analysed. We used the pair distribution function (PDF) obtained by Fourier Transform of the correlation function ${ }^{[25]}$ to capture any local structural changes induced by $\mathrm{Al}^{3+}$ intercalation. The PDF represents the probability of finding a pair of atoms separated by a distance $r$ (inter-atomic distances), and describes atomic ordering over short-to-intermediate distances. ${ }^{[26]}$ Using stoichiometric anatase $\mathrm{TiO}_{2}$ as structural model, the PDF data were successfully refined, with particularly good agreement for interatomic distances greater than $4 \AA$ (Figure 1d and Figures $\mathbf{S 1} \& \mathbf{S 2}$ in the Supporting Information), confirming that the parent anatase framework is maintained upon Al intercalation. The unit cell parameters remained almost unchanged with $a=3.7972(7) \AA$ and $c=9.478(3) \AA$ for stoichiometric anatase, and $a=3.802(1) \AA$

and $c=9.479(6) \AA$ for the discharged electrode. Negligible volume changes upon $\mathrm{Al}^{3+}$ intercalation have been reported previously for other materials. ${ }^{[14,16,17,27]}$ The PDF data for $r<4 \AA$ describes the local structure, and in this regime we find large deviations from the calculated stoichiometric anatase data. The difference curve highlights interatomic distances at $\sim 1.83 \AA$ and $\sim 2.6 \AA$ that are not captured by the anatase model. These features are less pronounced after charging (See Supporting Information) suggesting that they are induced by the intercalation of $A l^{3+}$. The residual peak observed at around 1.83 $\AA$ can be tentatively assigned to $\mathrm{Al}-X\left(X=\mathrm{F} / \mathrm{OH}^{[28-31]}, \mathrm{O}^{[32]}\right)$ while the sharp peak observed at $2.6 \AA$ is attributed to $\mathrm{F}-\mathrm{F}(\mathrm{OH})^{[28-31]}$ and short $\mathrm{O}-\mathrm{O}(\mathrm{OH})$ distances. Finally, we attempted to localize $\mathrm{Al}^{3+}$ ions within the structure by refining its occupancy in the titanium vacancies and the native interstitial sites. This refinement gives $0.11(3) \mathrm{Al}^{3+}$ within the titanium vacancies and $0.02(2) \mathrm{Al}^{3+}$ in the interstitial sites. Within the uncertainty of these data, these values agree with the measured insertion capacity, and suggest that inserted $\mathrm{Al}^{3+}$ ions preferentially occupy titanium vacancy sites.

Owing to its sensitivity to the local atomic-scale structure, high magnetic-field $(20 \mathrm{~T})$ solid-state ${ }^{27} \mathrm{Al}$ MAS NMR was used to probe the intercalation environments of the aluminium atoms (Figure 2). The one-dimensional ${ }^{27} \mathrm{Al}$ MAS NMR spectrum of the central transitions of the discharged electrode was reconstructed using two groups of resonances arising from inserted $\mathrm{Al}^{3+}$ ions and impurities, respectively (Figure $\mathbf{S 3}$ and Table S1). The latter group includes two contributions with a narrow dissymmetric peak at $\sim 101 \mathrm{ppm}$, assigned to $\mathrm{AlCl}_{4}{ }^{-}$and $\mathrm{Al}_{2} \mathrm{Cl}_{7}^{-[33]}$ coming from unwashed electrolyte, and a weaker intensity peak at $82 \mathrm{ppm}$, tentatively assigned to $\mathrm{Al}(\mathrm{OH})_{4} .^{-[34]}$

The main resonances, assigned to inserted $\mathrm{Al}^{3+}$ ions, consist of three overlapping broad lines with isotropic chemical shifts $\left(\delta_{\text {soo }}\right)$ assigned to tetra-, penta-, and hexa-coordinated aluminium $\left({ }^{[n]} \mathrm{Al}\right.$ with $n=4,5$, or 6 ). The line shapes are characteristic of disordered ${ }^{[n]} \mathrm{Al}$ sites and their reconstruction was achieved considering Gaussian distributions of $\delta_{\text {so }}$ and $\mathrm{C}_{\mathrm{Q}}$ (nuclear quadrupole coupling constant) values. ${ }^{[35]}{ }^{[4]} \mathrm{Al},{ }^{[5]} \mathrm{Al}$ and ${ }^{[6]} \mathrm{Al}$ resonances feature large isotropic chemical shift distributions (Figure 2a, Table S1) highlighting strong local disorder. This suggests that Al-intercalation sites exhibit a broad range of local anionic environments, including large radial and angular distortions, which we ascribe to substitutional disorder at both the titanium site (mixed occupancy by $\mathrm{Ti}^{4+}, \mathrm{Ti}^{3+}, \mathrm{Al}^{3+}$ and

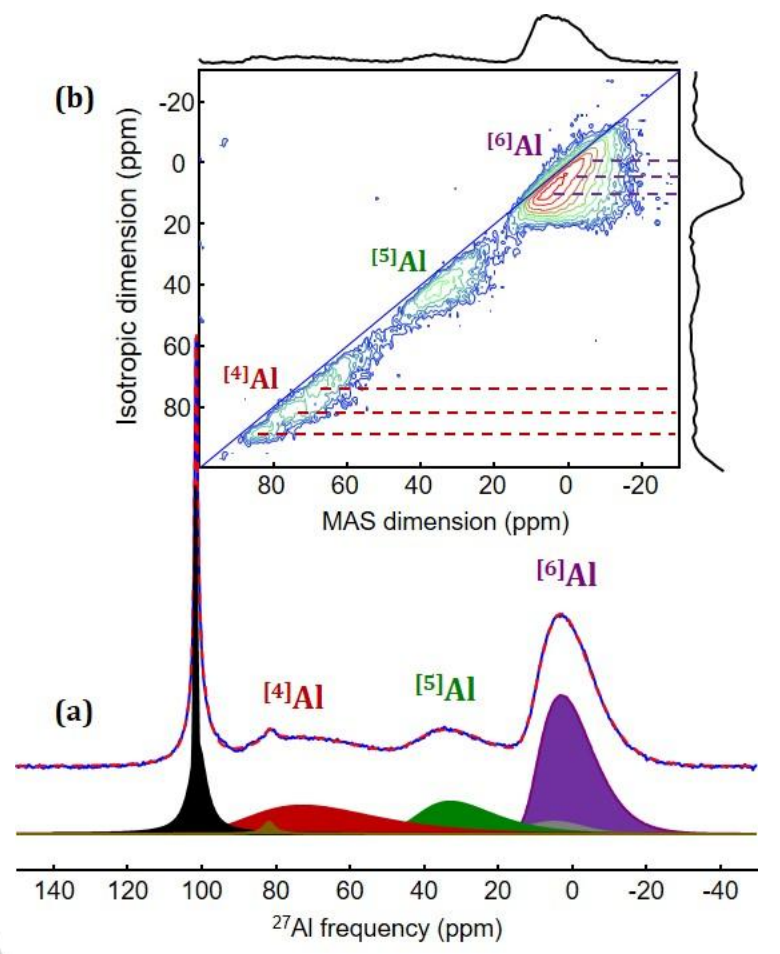

vacancies) and the anionic site (mixed occupancy by $\mathrm{O}^{2-}, \mathrm{OH}^{-}$, and $\mathrm{F}^{-}$), and possible additional $\mathrm{Al}^{3+}$ ion occupation of interstitial sites.

Figure 2. (a) Experimental (blue) and fitted (red dashed) one-dimensional ${ }^{27} \mathrm{Al}$ MAS $(60 \mathrm{kHz})$ NMR $(20 \mathrm{~T})$ spectrum of the central transitions of the aluminized $\mathrm{Ti}_{0.78} \square_{0.22} \mathrm{O}_{1.12} \mathrm{~F}_{0.40}(\mathrm{OH})_{0.48}$ sample. Details about the fit are given as Supporting Information (Figure S3, Table S1). The six central-contributions and the center band of ${ }^{[6]} \mathrm{Al}$ external transition pattern (in grey) are shown below. (b) Two-dimensional ${ }^{27} \mathrm{Al} 3 \mathrm{QMAS}$ spectrum of this sample. 4-, 5- and 6fold coordinated aluminium resonances are indicated. The dashed lines indicate the $\delta_{\text {so }}$ values of the suggested overlapping contributions within the broad lines assigned to ${ }^{[4]} \mathrm{Al}$ and ${ }^{[6]} \mathrm{Al}$ sites.

The relative intensities of the ${ }^{[n]} \mathrm{Al}$ resonances indicate the preferential formation of ${ }^{[6]} \mathrm{Al}(55 \%)$, versus ${ }^{[5]} \mathrm{Al}(18 \%)$, and ${ }^{\left[{ }^{[4]} \mathrm{Al}\right.}$ (27\%). To improve the spectral resolution of these ${ }^{[n]} \mathrm{Al}$ sites, a ${ }^{27} \mathrm{Al} 3 \mathrm{QMAS}$ spectrum was recorded (Figure 2b) highlighting a ${ }^{[6]} \mathrm{Al}$ resonance with a complex line shape, due to a large isotropic chemical shift distribution, correlated to a distribution of quadrupolar parameters. The asymmetric line-shape in the isotropic dimension suggests several overlapping contributions with $\delta_{\text {so }}$ values of about $10 \mathrm{ppm}, 5 \mathrm{ppm}$, and $0 \mathrm{ppm}$ (see dashed lines in Figure $\mathbf{2 b}$ ). These values are characteristic of $\mathrm{AlO}_{6-x} \mathrm{~F}_{x}{ }^{[36,37]}$ and $\mathrm{Al}(\mathrm{OH})_{6-x} \mathrm{~F}_{x}{ }^{[31]}$ environments, with $x \leq 2$, in aluminium oxy- and hydroxy-fluorides (in general, the higher the fluorine content, the lower the chemical shift). Due to the preferential location of $F$ atoms in the vicinity of titanium vacancies, ${ }^{[24]}$ the average $x$ value of the environment of the vacancies $\left(\square(\mathrm{O}, \mathrm{OH})_{6-x} \mathrm{~F}_{x}\right)$, and therefore of the Al atoms inserted in these sites, is $x=2.32 .^{[38]}$ The difference in the degree of fluorination $(x)$ is related to the presence of other cations $\left(\mathrm{Ti}^{4+}\right.$, $\left.\mathrm{Ti}^{3+}\right)$, that affect the chemical shift values with respect to the above mentioned reference samples. The ${ }^{27} \mathrm{Al} 3 \mathrm{QMAS}$ spectrum also reveals large isotropic chemical-shift distributions for the ${ }^{[4]} \mathrm{Al}$ and ${ }^{[5]} \mathrm{Al}$ sites, as indicated by the spread along the diagonal of the 2D map. Three ${ }^{[4]} \mathrm{Al}$ contributions (at $\sim 88 \mathrm{ppm}, \sim 78 \mathrm{ppm}$, 
and $70 \mathrm{ppm}$ ) appear just above the noise level; which are assigned to $\mathrm{Al}(\mathrm{O}, \mathrm{OH})_{4}$ units with $\mathrm{O}(\mathrm{OH})$ atoms bridging $\mathrm{Al}$ and 1 or $2 \mathrm{Ti}\left(\mathrm{Ti}^{\mathrm{III}}\right.$ or $\left.\mathrm{Ti}^{\mathrm{IV}}\right)$ atoms. We note that different coordination modes can be found in crystalline transition aluminas, which exhibit ${ }^{[4]} \mathrm{Al}$ and ${ }^{[6]} \mathrm{Al}$ sites, and that ${ }^{[4]} \mathrm{Al}$ and ${ }^{[5]} \mathrm{Al}$ sites are dominant in amorphous aluminium oxides. ${ }^{[39-41]}$

Complementary insights about the aluminium insertion mechanism were obtained from ${ }^{19} \mathrm{~F}$ solid-state NMR. ${ }^{19} \mathrm{~F}$ NMR is a suitable probe for $\mathrm{Al}^{3+}$ insertion in titanium vacancies because the ${ }^{19} \mathrm{~F}$ chemical shift strongly depends on the number and nature of the fluorine-nearest-neighbours. Figure 3a shows the ${ }^{19} \mathrm{~F}$ MAS NMR (7 $\left.\mathrm{T}\right)$ spectrum of the pristine $\mathrm{Ti}_{0.78} \square_{0.22} \mathrm{O}_{1.12} \mathrm{~F}_{0.40}(\mathrm{OH})_{0.48}$. The fluorine environments $\mathrm{Ti}^{\mathrm{iV}} \square_{2}-\mathrm{F}$, $\mathrm{Ti}^{\mathrm{iV}}{ }_{2} \square-\mathrm{F}$, and $\mathrm{Ti}^{\mathrm{iV}}{ }_{3}-\mathrm{F}$ were previously identified at $\delta_{\text {iso }}$ values of about 98 ppm, -4 ppm, and -88 ppm, respectively. ${ }^{[22,24]}$ To allow direct comparison and to avoid isotropic lines and spinning sidebands overlapping, ${ }^{19} \mathrm{~F}$ NMR spectra of the discharged electrode were also recorded at moderate field (Figure $\mathbf{3 b}$ ).

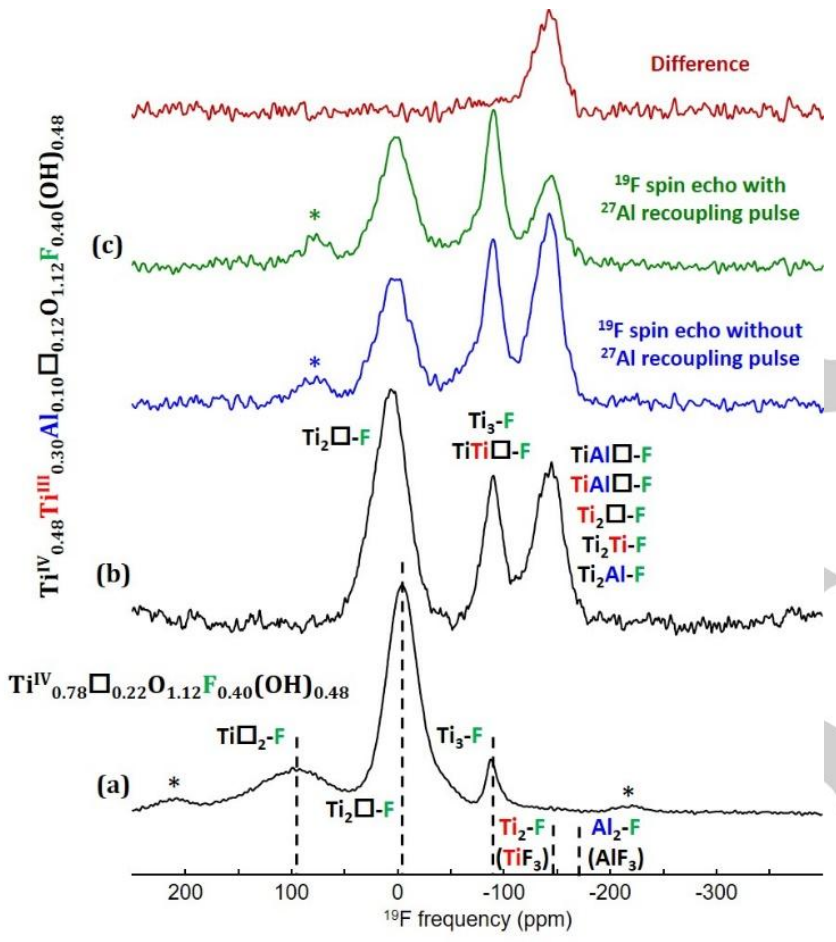

Figure 3. ${ }^{19} \mathrm{~F}$ MAS NMR (7 T) spectra of (a) $\mathrm{Ti}_{0.78} \square_{0.22} \mathrm{O}_{1.12} \mathrm{~F}_{0.40}(\mathrm{OH})_{0.48}(60$ $\mathrm{kHz})^{[22,24]}$ and (b) the aluminized sample $(64 \mathrm{kHz})$. (a) The asterisks indicate the main spinning sidebands. The dashed lines indicate the ${ }^{19} \mathrm{~F} \delta_{\text {so }}$ values of $\mathrm{Ti}^{\mathrm{IV}}{ }_{3}-\mathrm{F}, \mathrm{Ti}^{\mathrm{IV}}{ }_{2} \square-\mathrm{F}$, and $\mathrm{Ti}^{\mathrm{IV}} \square_{2}-\mathrm{F}$ environments in $\mathrm{Ti}_{0.78} \square_{0.22} \mathrm{O}_{1.12} \mathrm{~F}_{0.40}(\mathrm{OH})_{0.48}$ and the ${ }^{19} \mathrm{~F} \delta_{\text {iso }}$ values of $\mathrm{Ti}^{111}{ }_{2}-\mathrm{F}$ environment in $\mathrm{TiF}_{3}$ and $\mathrm{Al}_{2}-\mathrm{F}$ environment in $\mathrm{AlF}_{3}$. (b) Fit of the spectrum of the aluminized sample is given as Supporting Information (Figure S4, Table S2). Tentative assignment of the NMR resonances to various species in the aluminized sample are indicated with $\mathrm{Ti}^{\mathrm{IV}}$ in black and $\mathrm{Ti}^{\mathrm{III}}$ in red (Figure S5). (c) ${ }^{19} \mathrm{~F}^{-27} \mathrm{Al}$ double resonance MAS (60 $\mathrm{kHz}) \mathrm{NMR}(20 \mathrm{~T})$ experiments on the aluminized sample: difference (in red) between the ${ }^{19} \mathrm{~F}$ spin echo spectra without ${ }^{27} \mathrm{Al}$ irradiation (in blue) and with ${ }^{27} \mathrm{Al}$ irradiation (in green)

Our data show that aluminium insertion induces the disappearance of the line at $\sim 100 \mathrm{ppm}$, which is characteristic of $\mathrm{Ti}^{\mathrm{IV}} \square_{2}-\mathrm{F}$ species, providing additional evidence for the preferential insertion of aluminium at these titanium vacancies. We also observe large changes in the relative resonance intensities and moderate changes of the $\delta_{\text {sso }}$ values of the two other resonances, as well as the appearance of a new resonance at $\sim-143 \mathrm{ppm}$ (Figure S4 and Table S2). Finally, the main resonance at $0 \mathrm{ppm}$ characteristic of $\mathrm{Ti}^{\mathrm{iV}}{ }_{2} \square-\mathrm{F}$ slightly shifts to higher $\delta_{\text {iso }}$ value, with a decrease of the relative intensity of about $20 \%$ (Figure $3 \mathbf{b}$ ). Such a change can be due to the insertion of $\mathrm{Al}^{3+}$ into these single vacancies and/or due to the presence of reduced $\mathrm{Ti}^{\mathrm{III}}$ that can induce a resonance shift as discussed below.

To assign the ${ }^{19} \mathrm{~F}$ NMR resonances, we identified the numerous possible environments around fluorine atoms in the reduced sample and discussed their probability of occurrence. A random distribution of the fluoride ions on the anionic sites would give three-fold coordinate fluorine atoms as most probable. However, (i) as expected from crystal chemistry and demonstrated by ${ }^{19} \mathrm{~F}$ solid-state NMR, fluoride ions are preferentially located close to vacancies in the pristine compound ${ }^{[24]}$ i.e., are unlikely to be threefold coordinated, (ii) the reduced sample remains defective, and (iii) fluoride ions are two-fold coordinated in $\mathrm{TiF}_{3}{ }^{[42]}$ and in the various phases of $\mathrm{AlF}_{3}{ }^{[29,43,44]}$ (see Supporting Information). The intercalation of $\mathrm{Al}^{3+}$ ion in a titanium vacancy and the reduction of $\mathrm{a} \mathrm{Ti}^{4+}$ ion into a $\mathrm{Ti}^{3+}$ ion are both expected to induce a decrease of the $\delta_{\text {so }}$ value of the neighbouring ${ }^{19} \mathrm{~F}$ nucleus. Indeed, we first recall that an increase of the fluorine coordination leads to a decrease of the ${ }^{19} \mathrm{~F}$ chemical shift value as shown for ${ }^{19} \mathrm{~F}$ NMR chemical shift values of the environments $\mathrm{Ti}^{\mathrm{IV}} \square_{2}-\mathrm{F}, \mathrm{Ti}^{\mathrm{IV}}{ }_{2} \mathrm{\square}-\mathrm{F}$ and $\mathrm{Ti}^{\mathrm{IV}}{ }_{3}-\mathrm{F}$ in $\mathrm{Ti}_{0.78} \square_{0.22} \mathrm{O}_{1.12} \mathrm{~F}_{0.40}(\mathrm{OH})_{0.48}{ }^{[24]}$ Moreover, typical ${ }^{19} \mathrm{~F}$ NMR chemical shift values found in various $\mathrm{AlF}_{3}$ phases ${ }^{[45]}$ are - $172 \mathrm{ppm}\left(\mathrm{Al}_{2}-\mathrm{F}\right.$ species $)$. For ${ }^{19} \mathrm{~F}$ nucleus close to $\mathrm{Ti}^{\text {III }}$ as found in $\mathrm{TiF}_{3}$, it is about $-145 \mathrm{ppm}\left(\mathrm{Ti}^{\prime \prime \prime}{ }_{2}-\mathrm{F}\right.$ species). ${ }^{[22]}$ Based on these trends and on ${ }^{19} \mathrm{~F} \delta_{\text {iso }}$ values of the $F$ environments in $\mathrm{Ti}_{0.78} \square_{0.22} \mathrm{O}_{1.12} \mathrm{~F}_{0.40}(\mathrm{OH})_{0.48}$, we tentatively assign the ${ }^{19} \mathrm{~F}$ NMR resonances to some of the potential species expected in the aluminized sample (Figures $\mathbf{3}$ and S5, Tables $\mathbf{S} \mathbf{2}$ and $\mathbf{S 6}$ and more details in the Supporting Information).

${ }^{19} \mathrm{~F}-{ }^{27} \mathrm{Al}$ double-resonance MAS NMR experiments using a PMRESPDOR scheme ${ }^{[46]}$ (Figure 3c) were performed to explore differences in the ${ }^{19} \mathrm{~F}_{-}{ }^{27} \mathrm{Al}$ spin-spin and/or residual dipolar couplings, and thus the F-Al connectivities of the different fluorine sites. In the difference spectrum, the ${ }^{19} \mathrm{~F}$ resonances at $\sim 5 \mathrm{ppm}$ and $-90 \mathrm{ppm}$ disappeared, confirming that the corresponding $\mathrm{F}$ atoms are not connected to $\mathrm{Al}$ atoms, while the ${ }^{19} \mathrm{~F}$ resonance at $\sim-143 \mathrm{ppm}$ was observed with a relative dephased intensity of $52 \%$. Considering that a subset of ${ }^{27} \mathrm{Al}$ transitions might not be saturated by the ${ }^{27} \mathrm{Al}$ irradiation ${ }^{[46]}$ and that longer dephasing time could be required, this suggests that most of the corresponding $\mathrm{F}$ atoms are connected to Al. This supports the tentative assignment of these resonance to $\mathrm{Ti}^{\mathrm{iV}}{ }_{2} \mathrm{Al}-$ $\mathrm{F}$, Till AIL-F and $\mathrm{Ti}^{\mathrm{IV}} \mathrm{AI} \square-\mathrm{F}$ species, without excluding a possible contribution of $\mathrm{Ti}^{\mathrm{iV}}{ }_{2} \mathrm{Ti}^{\mathrm{Il}}-\mathrm{F}, \mathrm{Ti}^{\mathrm{lll}}{ }_{2} \square-\mathrm{F}$ species to this peak. A time-dependent ${ }^{27} \mathrm{Al}$ and ${ }^{19} \mathrm{~F}$ solid state NMR study has revealed subtle changes in the different environments of the probed nuclei (see Figures S6-S10, Tables S3-S6 and discussion in $\mathrm{SI}$ ). We have observed that $\mathrm{Al}^{3+}$ progressively moved from non-fluorinated ${ }^{[4]} \mathrm{Al}$ and ${ }^{[5]} \mathrm{Al}$ sites to ${ }^{[6]} \mathrm{Al}$ sites with the concomitant filling of some $\mathrm{Ti}_{2}^{\mathrm{iV}}{ }_{2} \square-\mathrm{F}$ vacancies giving $\mathrm{Ti}^{\mathrm{iV}}{ }_{2} \mathrm{Al}-\mathrm{F}$ species and fluorinated ${ }^{[6]} \mathrm{Al}$ site. We concluded that these changes associated with $\mathrm{Al}^{3+}$ migration were probably induced by frictional local heating during the NMR experiments. This point requires further investigation.

To better understand the insertion of $\mathrm{Al}$ into cation-deficient anatase $\mathrm{TiO}_{2}$, we performed a series of density functional theory 
(DFT) calculations to examine (i) the preferential insertion of $\mathrm{Al}^{3+}$ into one of the two available sites in paired-titanium-vacancy configurations; and (ii) the effect of local anion environment on the insertion mechanism at single-vacancy and interstitial sites.

To understand the preference for single $\mathrm{Al}^{3+}$ insertion within paired-titanium-vacancies, we performed calculations on a $\mathrm{Ti}_{126} \square_{2} \mathrm{O}_{248} \mathrm{~F}_{8}$ cell, and modelled the successive insertion of two $\mathrm{Al}^{3+}$ ions. The structural evolution of the supercell $\mathrm{Ti}_{126} \square_{1} \mathrm{O}_{248} \mathrm{~F}_{8}$ before and after the intercalation of one $\mathrm{Al}^{3+}$ is shown in Figure 4. For clarity, we show the double vacancy region and have labelled $F$ sites as $(A)$ to indicate bridging $F$-species $T_{2} \square-F$ and as (B) to indicate terminal $F$ in $T i \square_{2}-F$ (Figure 4a). For the first $\mathrm{Al}^{3+}$ insertion, we predict an intercalation energy of $-3.8 \mathrm{eV}$, which can be compared to the intercalation energy into an interstitial site of stoichiometric anatase $\mathrm{TiO}_{2}$ of $-1.2 \mathrm{eV}$ (Figure 5(a)) and shows the strong enhancement in the thermodynamic driving force for $\mathrm{Al}^{3+}$ insertion due to the presence of vacant cation sites. In this site, $\mathrm{Al}^{3+}$ is 6 -fold coordinated with an average bond length of $1.84 \AA$. Similar bond lengths were identified in the PDF data, and were shown to deviate from an ideal anatase structural model. This observation highlights the strong local distortion induced by the insertion of $\mathrm{Al}^{3+}$. To further illustrate this point, we can compare $M-X$ bond lengths and $M X_{6}$ coordination-polyhedron for $M=\mathrm{Li}^{+}$versus $M=\mathrm{Al}^{3+}$. We observe average bond distances of $2.02 \AA\left(\mathrm{Li}^{+}\right)$versus $1.84 \AA\left(\mathrm{Al}^{3+}\right)$ and $10.3 \AA^{3}\left(\mathrm{Li}^{+}\right)$versus $8.1 \AA^{3}\left(\mathrm{Al}^{3+}\right)$, again highlighting the strong polarizing power of $\mathrm{Al}^{3+}$.

For insertion of a subsequent second $\mathrm{Al}^{3+}$ ion into a pairedtitanium-vacancy, we predict an intercalation energy of only $2.4 \mathrm{eV}$. While this is still more thermodynamically favourable than intercalation into stoichiometric anatase $\mathrm{TiO}_{2}$, it is less favourable than if each aluminium ion were to singly occupy a different paired-vacancy site. The difference in intercalation energy for the first versus second inserted $\mathrm{Al}^{3+}$ can be explained by two factors. Insertion of the first $\mathrm{Al}^{3+}$ produces a strong contraction of the anion positions around the insertion site, and an associated expansion at the adjacent paired site. As discussed above, this is due to the strong polarizing power of $\mathrm{Al}^{3+}$, with short $\mathrm{Al}-(\mathrm{O} / \mathrm{F})$ distances indicating strong favourable Coulombic interactions between the inserted $\mathrm{Al}^{3+}$ and the host structure. Insertion of a second $\mathrm{Al}^{3+}$ causes the anion positions around the second site to contract somewhat, albeit less than for the first $\mathrm{Al}^{3+}$ insertion, and at the cost of expanding the coordination octahedron around the first $\mathrm{Al}^{3+}$. Now, both $\mathrm{Al}^{3+}$ have longer neighbouring $\mathrm{Al}-(\mathrm{O} / \mathrm{F})$ distances, indicating a less favourable Coulombic interaction between the intercalated ions and the host structure, than in the singly inserted case (Supporting Information). In addition, double-Al intercalation can form unfavourable $F$ coordination environments, possibly further disfavouring the second $\mathrm{Al}^{3+}$ insertion relative to the first. Upon intercalation of one $\mathrm{Al}^{3+}$ in one of the double vacancy sites, the bridging $F$-species $\mathrm{Ti}_{2} \square-\mathrm{F}$ (A) become three-fold coordinated, yielding $\mathrm{Ti}_{2} \mathrm{Al}-\mathrm{F}$ species (labelled $\mathrm{C}$ ), and the terminal fluorine atom in $T i{ }_{2}-F(C)$ becomes two-fold coordinated to one $A l$ and one $\mathrm{Ti}$, yielding $\mathrm{Ti}_{1} \mathrm{Al}_{1} \square-\mathrm{F}$ species (labelled $\mathrm{D}$ ). Based on the above-mentioned tentative assignments of the ${ }^{19} \mathrm{~F}$ resonances, we note that the species $(B)$ and $(C)$ can then be attributed to $\mathrm{Ti}_{2}{ }_{2}^{\mathrm{IV}} \mathrm{Al}-\mathrm{F}$ and $\mathrm{Ti} \mathrm{Til}^{\mathrm{III}} \mathrm{AI}-\mathrm{F} / \mathrm{Ti}^{\mathrm{IV}} \mathrm{AI} \mathrm{C}-\mathrm{F}$ species, respectively. a)

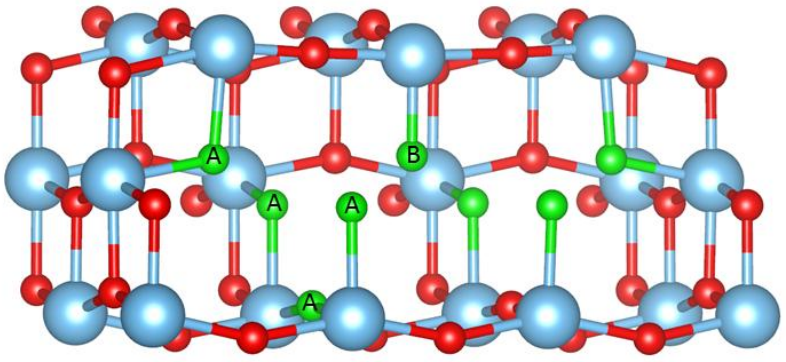

b)

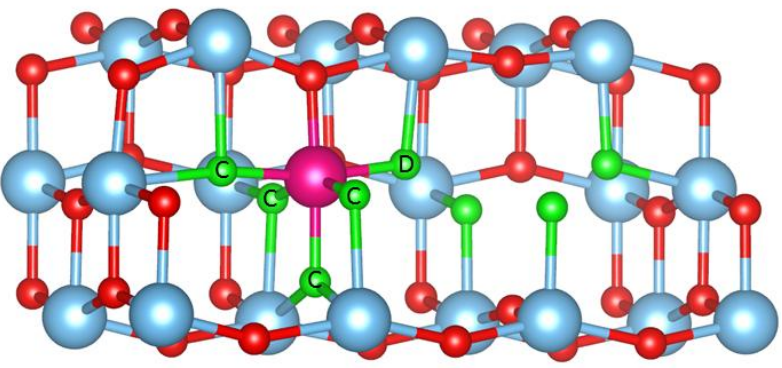

Figure 4. Structural representations of the supercell featuring double vacancy $\mathrm{Ti}_{126} \square_{2} \mathrm{O}_{248} \mathrm{~F}_{8}$ before a) and after b) the introduction of one $\mathrm{Al}^{3+}$, i.e., $\mathrm{Ti}_{126} \square_{1} \mathrm{Al}_{1} \mathrm{O}_{248} \mathrm{~F}_{8}$. The blue, red, green and magenta spheres represent titanium, oxygen, fluorine and aluminum atoms, respectively. Labels $A-D$ refer to (A) bridging $F$-species $\mathrm{Ti}_{2} \square-\mathrm{F}$, (B) terminal $F$ in $\mathrm{Ti}_{2}-\mathrm{F}$, (C) F-species in $\mathrm{Ti}_{2} \mathrm{Al}-\mathrm{F}$ and (D) F-species in TiAlD-F.

We have also investigated how varying the local anion environment at single-Ti vacancy sites affects the $\mathrm{Al}^{3+}$ insertion energies. Figure $\mathbf{5 b}$ shows calculated intercalation energies for $\mathrm{Al}^{3+}$ into $\mathrm{Ti}_{127} \square_{1} \mathrm{O}_{252} X_{4}$ single-vacancy supercells, with the type of single-valent anions $(X)$ neighbouring the vacancy varied from fully fluorinated $(4 \mathrm{~F})$ to hydroxy-fluorinated $(3 \mathrm{~F}+1 \mathrm{OH}, 2 \mathrm{~F}+2 \mathrm{OH}$, $1 \mathrm{~F}+3 \mathrm{OH})$ to fully hydroxylated $(4 \mathrm{OH})$. The calculated intercalation energies, as a function of $X$ are shown in Figure $\mathbf{5 b}$. For a purely-fluorine-compensated vacant site, the intercalation energy of $\mathrm{Al}^{3+}$ is $-3.1 \mathrm{eV}$. Partial or complete replacement of $\mathrm{F}$ with $\mathrm{OH}$ neighbouring the vacancy sites reduces the absolute value of the intercalation energy to $\sim-2.5 \mathrm{eV}$, indicating that hydroxy-fluorinated environments are generally less accommodating of $\mathrm{Al}^{3+}$. According to ${ }^{19} \mathrm{~F}$ NMR, only a small proportion of single-vacant sites are capable of accommodating $\mathrm{Al}^{3+}$ ions. Our calculations indicate that these are likely to be fluorine-rich vacancy environments, which are statistically less likely than hydroxylated or mixed-hydroxy-fluorinated environments. ${ }^{[47]}$ This suggests that the poor ability of $\mathrm{Al}^{3+}$ to be inserted in single vacant site is primary due to the local environment of the vacancy.

To better understand how anionic environment affects the intercalation properties of neighbouring interstitial sites, we performed additional DFT calculations with Al atoms occupying interstitial sites adjacent to a single vacancy. For each anion combination, we plotted all inequivalent vacancy-adjacent positions in Figure $\mathbf{5 b}$ as grey points. The intercalation energies show a broad spread, due to the variation in the local geometry (both the local anion configuration, and the interstitial position relative to the vacancy site). Furthermore, in all cases some of these intercalation energies are more favourable than for insertion at an isolated interstitial site in pristine anatase $\mathrm{TiO}_{2}$. Analysis of the $\mathrm{Al}-(\mathrm{O} / \mathrm{F})$ coordination modes from our calculations revealed that $\mathrm{Al}^{3+}$ located in Ti-vacancy sites strictly 
adopts 6-fold coordination, while $\mathrm{Al}^{3+}$ inserted into interstitial sites is under-coordinated, specifically being 5 -fold coordinated, further explaining the ${ }^{27} \mathrm{Al}$ NMR data. The occurrence of 4-fold coordination mode was, however, not captured by DFTcalculations. We postulate that this might be due to the fact that electrochemical insertion is performed under non-equilibrium conditions. Time-dependent ${ }^{27} \mathrm{Al}$ NMR experiments, indeed, revealed that these "4-coordinate" insertion sites are unstable with their proportion decreasing upon aging. Another potential contributing factor is the possibility of structural heterogeneity within our experimental samples, or additional geometric distortions due to defect-defect interactions at high $(\mathrm{F} / \mathrm{OH})$ doping levels, which may potentially lead to off-centre $\mathrm{Al}^{3+}$ forming a 4-fold coordination mode, i.e., 4+2.
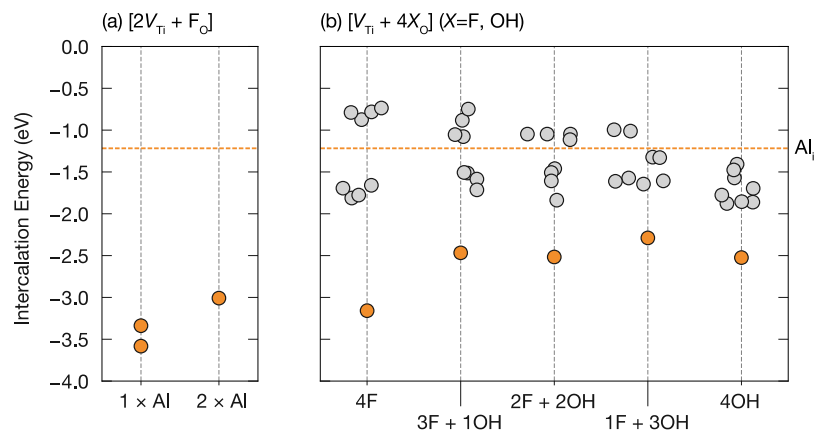

Figure 5. Intercalation energies of $\mathrm{Al}^{3+}$. (a) Average intercalation energies for $1 \mathrm{Al}$ and $2 \mathrm{Al}$ into a double-vacancy of the $\mathrm{Ti}_{126} \square_{2} \mathrm{O}_{248} \mathrm{~F}_{8}$ supercell. (b) Intercalation energies for Al into a single-vacancy of the $\mathrm{Ti}_{127} \square_{1} \mathrm{O}_{252} X_{4}$ supercell for $X=\{\mathrm{F}, \mathrm{OH}\}$. The horizontal dashed line shows the intercalation energy for $\mathrm{Al}^{3+}$ in stoichiometric anatase $\mathrm{TiO}_{2}$ at an interstitial site. Source: source data, figure files, and plotting scripts are available under the CC-BY-4.0 license as part of reference ${ }^{[48]}$.

\section{Conclusion}

To summarize, we investigated the insertion mechanism of $\mathrm{Al}^{3+}$ into defective anatase. About $\sim 0.10 \mathrm{Al}^{3+}$ per formula unit can be electrochemically inserted in the structure via solid-solution behaviour with negligible volume changes. Pair distribution function analysis revealed that $A l^{3+}$ induces local distortions, that were accurately captured by DFT-calculations. Such local distortions affect the insertion properties of neighbouring pairs of Ti vacancies, providing a possible explanation for the limited number of $\mathrm{Al}^{3+}$ that can be reversibly inserted. The intercalation mechanism is found to involve a number of different types of host sites; specifically, native interstitial sites, single-Ti-vacancy sites, and double-Ti-vacancy sites. $\mathrm{Al}^{3+}$ adopts a 6-fold coordination mode in Ti-vacancy sites, while $\mathrm{Al}^{3+}$ is undercoordinated when occupying interstitial sites, as shown by ${ }^{27} \mathrm{Al}$ NMR and DFT-calculations. Within the double-vacancy, inserting two $\mathrm{Al}^{3+}$ is less favourable than inserting one $\mathrm{Al}^{3+}$. This corresponds to about $40 \%$ of the total number of vacancies, which translates to 0.045 vacancy per formula unit that readily accommodate $\mathrm{Al}^{3+}$ ions. Moreover, a limited number of fullyfluorinated single-vacancy sites are predicted to be electrochemically active, highlighting the key role of the local anion environment. Local anion configurations also affect the insertion properties of interstitial sites, which may also contribute to the insertion mechanism. Overall, this work highlights specific structural features induced by the intercalation electrochemistry of tri-valent cation which should be considered when designing new electrode materials for polyvalent batteries.

\section{Acknowledgements}

The research leading to these results has received funding from the French National Research Agency under Idex@Sorbonne University for the Future Investments program (No. ANR-11IDEX-0004-02) and by the German Federal Ministry of Education and Research (BMBF) through funding by the "Sino German TU9 network for electromobility" under the grant reference number $16 \mathrm{~N} 11929$. Financial support from the IRRMN-THC Fr3050 CNRS for conducting the research is gratefully acknowledged. B. J.M. acknowledges support from the Royal Society (UF130329 \& URF\R\191006). This work made use of the ARCHER UK National Supercomputing Service (http://www.archer.ac.uk), via the membership of the UK's HPC Materials Chemistry Consortium, which is funded by EPSRC (EP/L000202). The work done at the Advanced Photon Source, an Office of Science User Facility operated for the U.S. Department of Energy (DOE) Office of Science by Argonne National Laboratory, was supported by the U.S. DOE under Contract No. DE-AC02-06CH11357. D.D, C.L, M.B wish to thank the French fluorine network for continuous support.

Keywords: Polyvalent ion batteries $\cdot{ }^{27} \mathrm{Al}$ and ${ }^{19} \mathrm{~F}$ solid state $\mathrm{NMR} \cdot$ vacancy $\bullet$ local distortion $\bullet$ insertion mechanism

1] J.-M. Tarascon, Nat Chem 2010, 2, 510-510.

[2] C. P. Grey, J. M. Tarascon, Nat Mater 2017, 16, 45-56.

[3] K. Kubota, M. Dahbi, T. Hosaka, S. Kumakura, S. Komaba, The Chemical Record 2018, 18, 459-479.

[4] P. Canepa, G. Sai Gautam, D. C. Hannah, R. Malik, M. Liu, K. G. Gallagher, K. A. Persson, G. Ceder, Chem. Rev. 2017, 117, 42874341.

[5] H. Yang, H. Li, J. Li, Z. Sun, K. He, H.-M. Cheng, F. Li, Angewandte Chemie International Edition 2019, 58, 11978-11996.

[6] T. Leisegang, F. Meutzner, M. Zschornak, W. Münchgesang, R. Schmid, T. Nestler, R. A. Eremin, A. A. Kabanov, V. A. Blatov, D. C. Meyer, Front. Chem. 2019, 7, DOI 10.3389/fchem.2019.00268.

[7] G. A. Elia, K. Marquardt, K. Hoeppner, S. Fantini, R. Lin, E. Knipping, W. Peters, J.-F. Drillet, S. Passerini, R. Hahn, Adv. Mater. 2016, 28, 7564-7579.

[8] J. Shi, J. Zhang, J. Guo, ACS Energy Lett. 2019, 4, 2124-2129.

[9] M.-C. Lin, M. Gong, B. Lu, Y. Wu, D.-Y. Wang, M. Guan, M. Angell, C. Chen, J. Yang, B.-J. Hwang, H. Dai, Nature 2015, 520, 324-328.

[10] M. Walter, K. V. Kravchyk, C. Böfer, R. Widmer, M. V. Kovalenko, Advanced Materials 2018, 30, 1705644.

[11] D. B. Le, S. Passerini, F. Coustier, J. Guo, T. Soderstrom, B. B. Owens, W. H. Smyrl, Chem. Mater. 1998, 10, 682-684.

[12] W. Wang, B. Jiang, W. Xiong, H. Sun, Z. Lin, L. Hu, J. Tu, J. Hou, H. Zhu, S. Jiao, Scientific Reports 2013, 3, srep03383.

[13] B. Lee, H. R. Lee, T. Yim, J. H. Kim, J. G. Lee, K. Y. Chung, B. W Cho, S. H. Oh, J. Electrochem. Soc. 2016, 163, A1070-A1076.

[14] L. Geng, J. P. Scheifers, C. Fu, J. Zhang, B. P. T. Fokwa, J. Guo, ACS Appl. Mater. Interfaces 2017, 9, 21251-21257.

[15] H. Wang, Y. Bai, S. Chen, X. Luo, C. Wu, F. Wu, J. Lu, K. Amine, ACS Appl. Mater. Interfaces 2015, 7, 80-84.

[16] A. VahidMohammadi, A. Hadjikhani, S. Shahbazmohamadi, M. Beidaghi, ACS Nano 2017, 11, 11135-11144.

[17] L. Geng, J. P. Scheifers, J. Zhang, K. N. Bozhilov, B. P. T. Fokwa, J. Guo, Chem. Mater. 2018, 30, 8420-8425.

[18] S. K. Das, T. Palaniselvam, P. Adelhelm, Solid State Ionics 2019, 340 115017.

[19] S. Wang, K. V. Kravchyk, S. Pigeot-Rémy, W. Tang, F. Krumeich, M. Wörle, M. I. Bodnarchuk, S. Cassaignon, O. Durupthy, S. Zhao, C. Sanchez, M. V. Kovalenko, ACS Appl. Nano Mater. 2019, 2, 64286435.

[20] M. Wagemaker, W. J. H. Borghols, F. M. Mulder, J. Am. Chem. Soc. 2007, 129, 4323-4327. 
[21] L. Wu, D. Buchholz, D. Bresser, L. Gomes Chagas, S. Passerini, Journal of Power Sources 2014, 251, 379-385.

[22] T. Koketsu, J. Ma, B. J. Morgan, M. Body, C. Legein, W. Dachraoui, M. Giannini, A. Demortière, M. Salanne, F. Dardoize, H. Groult, O. J. Borkiewicz, K. W. Chapman, P. Strasser, D. Dambournet, Nature Materials 2017, 16, 1142

[23] T. Koketsu, J. Ma, B. J. Morgan, M. Body, C. Legein, W. Dachraoui, M. Giannini, A. Demortière, M. Salanne, F. Dardoize, H. Groult, O. J. Borkiewicz, K. W. Chapman, P. Strasser, D. Dambournet, Nat. Mater. 2017, 16, 1142-1148.

[24] W. Li, D. Corradini, M. Body, C. Legein, M. Salanne, J. Ma, K. W. Chapman, P. J. Chupas, A.-L. Rollet, C. Julien, K. Zhagib, M. Duttine, A. Demourgues, H. Groult, D. Dambournet, Chem. Mater. 2015, 27, 5014-5019.

[25] D. A. Keen, J Appl Cryst, J App/ Crystallogr 2001, 34, 172-177.

[26] T. Egami, S. J. L. Billinge, Underneath the Bragg Peaks: Structural Analysis of Complex Materials, Elsevier, 2003.

[27] J. Jiang, H. Li, J. Huang, K. Li, J. Zeng, Y. Yang, J. Li, Y. Wang, J. Wang, J. Zhao, ACS Appl. Mater. Interfaces 2017, 9, 28486-28494.

[28] P. Daniel, A. Bulou, M. Rousseau, J. Nouet, J. L. Fourquet, M. Leblanc, R. Burriel, J. Phys.: Condens. Matter 1990, 2, 5663-5677.

[29] A. Le Bail, C. Jacoboni, M. Leblanc, R. De Pape, H. Duroy, J. L. Fourquet, Journal of Solid State Chemistry 1988, 77, 96-101.

[30] D. Dambournet, A. Demourgues, C. Martineau, S. Pechev, J. Lhoste, J. Majimel, A. Vimont, J.-C. Lavalley, C. Legein, J.-Y. Buzaré, F. Fayon, A. Tressaud, Chem. Mater. 2008, 20, 1459-1469.

[31] D. Dambournet, A. Demourgues, C. Martineau, E. Durand, J. Majimel, A. Vimont, H. Leclerc, J.-C. Lavalley, M. Daturi, C. Legein, J.-Y. Buzaré, F. Fayon, A. Tressaud, J. Mater. Chem. 2008, 18, 2483.

[32] B. Ollivier, R. Retoux, P. Lacorre, D. Massiot, G. Férey, Journal of Materials Chemistry 1997, 7, 1049-1056.

[33] C. Ferrara, V. Dall'Asta, V. Berbenni, E. Quartarone, P. Mustarelli, The Journal of Physical Chemistry C 2017, 121, 26607-26614.

[34] J. W. Akitt, Progress in Nuclear Magnetic Resonance Spectroscopy 1989, 21, 1-149.

[35] D. Massiot, F. Fayon, M. Capron, I. King, S. Le Calvé, B. Alonso, J.-O. Durand, B. Bujoli, Z. Gan, G. Hoatson, Magnetic Resonance in Chemistry 2002, 40, 70-76.

[36] W. Zhang, M. Sun, R. Prins, J. Phys. Chem. B 2002, 106, 1180511809.

[37] P. J. Chupas, C. P. Grey, Journal of Catalysis 2004, 224, 69-79.

[38] J. Ma, W. Li, B. J. Morgan, J. Światowska, R. Baddour-Hadjean, M. Body, C. Legein, O. J. Borkiewicz, S. Leclerc, H. Groult, F. Lantelme, C. Laberty-Robert, D. Dambournet, Chem. Mater. 2018, 30, 30783089.

[39] S. K. Lee, S. B. Lee, S. Y. Park, Y. S. Yi, C. W. Ahn, Phys. Rev. Lett. 2009, 103, 095501

[40] S. K. Lee, S. Y. Park, Y. S. Yi, J. Moon, J. Phys. Chem. C 2010, 114, 13890-13894.

[41] V. Sarou-Kanian, A. N. Gleizes, P. Florian, D. Samélor, D. Massiot, C. Vahlas, The Journal of Physical Chemistry C 2013, 117, 21965-21971.

[42] R. Hoppe, St. Becker, Zeitschrift für anorganische und allgemeine Chemie 1989, 568, 126-135.

[43] P. Daniel, A. Bulou, M. Rousseau, J. Nouet, M. Leblanc, Physical Review B 1990, 42, 10545-10552.

[44] N. Herron, D. L. Thorn, R. L. Harlow, G. A. Jones, J. B. Parise, J. A Fernandez-Baca, T. Vogt, Chemistry of Materials 1995, 7, 75-83.

[45] A. Sadoc, M. Biswal, M. Body, C. Legein, F. Boucher, D. Massiot, F. Fayon, Solid State Nuclear Magnetic Resonance 2014, 59-60, 1-7.

[46] E. Nimerovsky, R. Gupta, J. Yehl, M. Li, T. Polenova, A. Goldbourt, Journal of Magnetic Resonance 2014, 244, 107-113.

[47] J. Ma, T. Koketsu, B. J. Morgan, C. Legein, M. Body, P. Strasser, D. Dambournet, Chem. Commun. 2018, 54, 10080-10083.

[48] B. Morgan, Computational Supporting Dataset: Atomic Insights into Aluminium-lon Insertion in Defective Hydroxyfluorinated Anatase for Batteries.Bath: University of Bath Research Data Archive. doi.org/10.15125/BATH-00815. 


\section{Entry for the Table of Contents}

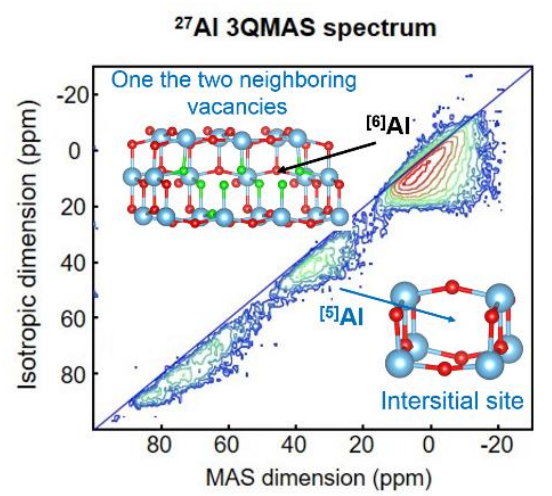

The intercalation mechanism of high-charge $\mathrm{Al}^{3+}$ ions in cationic-defective anatase was elucidated providing fundamental insights into key factors that impact the total number of inserted ions. Such factors are the nature of insertion sites, their surrounding anions and the polarizing power of $\mathrm{Al}^{3+}$. 